\title{
Systematic Development of Knowledge Management in State-owned Enterprises
}

\author{
Yunfei $\mathrm{Xu}^{1, *}$, Xinsheng Zhang ${ }^{2}$, Jianmin Wang ${ }^{3}$, Bingxin Zeng ${ }^{4}$ \\ 1,2,4 State Grid Energy Research Institute Co. LTD,Changping, 102209, Beijing, China \\ ${ }^{3}$ State Grid Beijing Changping Power Supply Company, Changping, 102200, Beijing, China \\ *Corresponding author. Email: xuyunfei@sgeri.sgcc.com.cn
}

\begin{abstract}
The continuous development of science and technology has brought profound influence and changes to the production and operation of enterprises. Especially with the development and progress of the knowledge economy era, various resources with knowledge as the core have gradually become a new type of enterprise resources, and their position and role in enterprises are becoming more and more important, and enterprises' understanding and importance of knowledge management have been improved unprecedentedly. This paper takes the construction of knowledge management system in large state-owned enterprises as the research object, summarizes the related concepts of knowledge management, analyzes the significance of the construction of knowledge management system in large state-owned enterprises, and expounds the steps of the construction of knowledge management system in large stateowned enterprises. This study aims to provide some concrete guidance and reference for the research and practice of knowledge management.
\end{abstract}

Keywords: State-owned enterprises, Knowledge management, Implementation steps4.1. Hypothesis 1

\section{INTRODUCTION}

"Whether in the West or the East, knowledge has always been regarded as the existence of Being, but almost overnight, it has become the existence of Doing, thus becoming a resource and a practical tool."

\section{- Peter Drucker}

In the era of knowledge economy, knowledge management theory has been gradually accepted by all walks of life. Many well-known enterprises at home and abroad, such as Apple, Microsoft, IBM, Huawei, Baidu, etc., have introduced knowledge management into enterprises and regarded knowledge management as an important part of enterprise management. Knowledge is the foundation for enterprises to create new knowledge and cultivate new talents and technologies, and it is also the key factor for enterprises to improve their competitiveness. The innovation of enterprises depends not only on the effective application of knowledge, but also on the innovation of knowledge. Technological innovation is a process of knowledge. However, if an enterprise wants to improve its innovation ability, it is far from enough to rely on a single knowledge, but it needs the collection and synthesis of multiple knowledge and abilities. Only by using knowledge accumulation, knowledge mining, knowledge integration, knowledge application and knowledge innovation, and realizing the accumulation and improvement of capabilities in the process of knowledge management, can enterprises achieve technological innovation, thus realizing enterprise development and improving competitiveness. Large state-owned enterprises are typical talent-and knowledge-intensive organizations, in which knowledge is constantly generated, flowed, transformed and applied, and then new knowledge is generated. Therefore, the effective management of massive knowledge is particularly important. The growth of talents, the improvement of enterprise competitiveness and the development of enterprises all depend on the level and achievements of knowledge management [1].

With competitive advantage, enterprises must be able to manage knowledge resources. Presently, science and technology are gradually prevailing in the application fields of enterprises, and knowledge is spread and multiplied more cheaply and rapidly than ever before, which means that once competitors get the same knowledge, the advantages of enterprises will soon be lost. In order to make the competitive advantage 
last, enterprises must manage knowledge resources and dig out good practices. Enterprise knowledge management can enable enterprises to acquire knowledge and apply knowledge. Knowledge management is not only pure technical knowledge, but also includes the compatibility of technology with the whole organization (such as production, finance, marketing, etc.). Many enterprises have begun to realize the importance of knowledge management, and incorporate the concept and practice of knowledge management into enterprise management. However, this knowledge management method is mostly fragmented, and it is rarely systematically designed based on the whole process of enterprise knowledge management, which leads to the inability of knowledge to effectively flow, share, and even apply and innovate within enterprises, thus making it difficult to meet the needs of enterprise knowledge management [2]. Therefore, enterprises need to consider the whole situation from a systematic point of view, strengthen the top-level design of knowledge management, and effectively match business process with knowledge management process, so as to systematically manage enterprise knowledge, carry out knowledge management efficiently, truly transform knowledge productivity into competitive advantage, and realize the sustainable development of enterprises.

\section{CONCEPTS RELATED TO KNOWLEDGE MANAGEMENT}

To explore the concept of knowledge management, a correct understanding of knowledge is the priority. Knowledge is people's cognition, judgment or skills acquired through study, practice or exploration. Knowledge can be explicit or implicit. It can be organized or personal. Knowledge can include factual knowledge, principle knowledge, skill knowledge and interpersonal knowledge. According to different knowledge contents, knowledge can be divided into explicit knowledge and tacit knowledge. Explicit knowledge is knowledge that can be expressed in words and numbers and can be easily exchanged and shared in the form of hard data, such as editing procedures or universal principles. Tacit knowledge is highly personalized and difficult to format, and subjective understanding, intuition and premonition all belong to this category, such as the experience of enterprise employees. Tacit knowledge and explicit knowledge can be transformed into each other. According to different knowledge subjects, knowledge can be divided into personal knowledge and organizational knowledge. Personal knowledge is the knowledge acquired by employees through past experience and training. Organizational knowledge is the knowledge owned by the organization, including the knowledge generated by its own development within the organization and the knowledge that is useful for the survival and development of the organization outside the organization (this part can be internalized as organizational knowledge). Personal knowledge and organizational knowledge can also be transformed into each other. Personal knowledge can be refined, summarized and popularized to form organizational knowledge, and organizational knowledge can also be transformed into personal knowledge of employees through training and learning.

Knowledge Management (KM) is a new management trend and method in the era of new network economy, and it is one of the most important means to build a learning organization. Knowledge management in a narrow sense mainly aims at knowledge itself, including the management of knowledge creation, acquisition, processing, storage, dissemination and application. Knowledge management in a broad sense includes not only the management of knowledge itself, but also the management of various knowledge-related resources and intangible assets, involving the omni-directional and whole-process management of knowledge assets, knowledge facilities, knowledge organizations, knowledge activities and knowledge personnel [3]. Knowledge management is a dynamic, continuous and multidimensional organizational phenomenon. Knowledge management includes interdependent process of knowledge creation, knowledge storage and retrieval, knowledge transfer and knowledge application.

\section{PROCESS OF KNOWLEDGE MANAGEMENT}

According to the research of Wang (2004), the process of knowledge management can be divided into four links, namely, knowledge produce, knowledge stockpile, knowledge communication and knowledge application [4]. These four segments into which knowledge management is divided can be defined as "PSCA closed loop". "PSCA closed loop" is a complete management system, and the four links are mutually influenced and interact, and they can conduct effective conduction among each other.

Knowledge Produce: To manage knowledge, the first thing that needs to be solved is the acquisition and creation of knowledge. Acquiring knowledge refers to precipitating existing knowledge and forming explicit knowledge. And creation refers to the summary and creation of knowledge in carrying out specific business and work.

Knowledge Stockpile: Everyone and every enterprise will organize knowledge according to their own needs, and there is no standard knowledge structure. In the process of knowledge accumulation, knowledge is "recorded" by creating a "knowledge base" for management and organization, and transforming tacit 
knowledge and explicit knowledge to form knowledge accumulation.

Knowledge Communication: Knowledge communication is very important to the flow and sharing of knowledge in different environments. Knowledge is transmitted and shared through direct or indirect communication to meet the needs of different subjects for various kinds of knowledge.

Knowledge Application: to analyze the demand and structure of knowledge, and create the "driving force" of knowledge by establishing knowledge management system and supporting knowledge management mechanism. To pay attention to knowledge feedback in the process of knowledge application, form standardized feedback steps, and combine with knowledge evaluation.

In the process of the continuous implementation and management of the four links, knowledge itself has been continuously expanded and added value.

\section{STEPS TO BUILD THE KNOWLEDGE MANAGEMENT SYSTEM OF STATE- OWNED ENTERPRISES}

According to the theory of enterprise knowledge management [5], the steps of constructing the knowledge management system of state-owned enterprises are divided into the following five steps.

\subsection{Learning and Understanding}

Learning and understanding is the first step for enterprises to implement knowledge management. The main task is to unify their cognition of knowledge management, sort out the significance of knowledge management to enterprise management, and evaluate the current situation of enterprise knowledge management. To help enterprises understand whether knowledge management is needed and determine the correct direction of knowledge management implementation. The main work includes: to comprehensive and complete knowledge management, knowledge management cognitive training for middle and highlevel enterprises, especially for high-level enterprises to understand knowledge management. To use knowledge management maturity model and other evaluation tools to evaluate the current situation of enterprise knowledge management and analyse the main problems of enterprise management through investigation; Evaluate the long-term and short-term effects of knowledge management for enterprises, so as to provide decision support for promoting knowledge management practice. To develop knowledge management strategy and determine advance direction. In this process, the enterprises need to pay special attention to the promotion and guidance of management and middlelevel cadres, so that they can establish the concept of knowledge management, master the methods of knowledge management, and gradually create an enterprise culture atmosphere of knowledge management.

\subsection{Planning Formulation}

The promotion of knowledge management is a systematic project, which requires detailed planning and preparation. On the basis of fully recognizing the needs of enterprises, detailed planning is also an important link to ensure the implementation effect of knowledge management. This link is mainly through a detailed analysis of the current situation of knowledge management, knowledge types, combined with business process and other perspectives of knowledge management planning. In planning, knowledge management should be fully integrated into enterprise management, so as to give full play to the implementation effect of knowledge management. The main work includes: to develop knowledge management planning from strategy, business process and position. To conduct authenticity analysis of current situation of enterprise management and development of knowledge management. To formulate strategic objectives and implementation strategies related to knowledge management and rationalize the process. To carry out Demand analysis and planning of knowledge management landing. To establish the theoretical foundation of knowledge management in an all-round way in enterprises.

\subsection{Pilot Implementation}

This stage is the continuation and practice of the planning stage and the proper departments and process are selected according to the planning to carry out knowledge management practice according to the planning basis. To evaluate the knowledge management plan from the short-term effect, and revise it according to the problems in the pilot. Because the task characteristics of different business systems are different, and the knowledge they need to complete the task is also different, it is necessary to choose a knowledge management method that adapts to the characteristics of enterprises according to the task characteristics and knowledge application characteristics of different business systems. Therefore, at this stage, the key point is to comb the knowledge system according to the business model of the enterprise, and analyze the results of knowledge combing to determine the specific strategies and promotion behaviors of knowledge management.

The main tasks and key links of the pilot implementation phase mainly include two aspects: First, the inter-group special leading group should be established in the company to establish an internal 
coordination system from the top to the bottom. Secondly, according to the work plan and theoretical scheme, the pilot units or departments with mature conditions should be selected to carry out the work. According to the specific condition in the construction process of the knowledge management system of the pilot units or departments, the necessary amendments should be made to the original plans appropriately to form a relatively fixed and perfect work plan.

\subsection{Comprehensive Promotion}

On the basis of constantly revising the knowledge management plan in the pilot stage, knowledge management will be widely popularized in enterprises to fully realize its value. Promotion content includes: the practice of knowledge management pilot departments and the replication in other departments of enterprises. Knowledge management is fully integrated into enterprise business process and value chains. The knowledge management system was initially established. To make comprehensive application of knowledge management system and to realize the comprehensive operation and institutionalization of knowledge management promotion plans such as community, learning organization and brainstorming.

The main task of the comprehensive promotion stage is to summarize the work experience gained in the pilot implementation process, effectively copy and promote it according to the formed management template, and make the pilot experience of knowledge management penetrate into the whole scope of the company, thus completing the construction of the whole company's knowledge management system. The main difficulties are: first, to grasp the overall situation and effectively manage the implementation process of knowledge management. The second is to integrate knowledge management into business process and daily work to promote the coordinated development of culture, management and technology. The third is to establish an effective incentive mechanism and performance system for knowledge management, to control human factors such as the change of ideas, and to redistribute benefits.

\subsection{Institutionalization}

Institutionalization stage is not only the end of the implementation of knowledge management projects, but also a new beginning of enterprise knowledge management and a process of self-improvement. To complete this stage, the enterprise need to redefine its strategy, reorganize its organizational structure and business process, and accurately evaluate the value of knowledge management in the enterprise. The main task of this stage is to summarize and optimize the process, environment, management methods and management tools through the operation of the knowledge management system in a certain period of time, to form relatively stable management and summary system related documents, and to fully integrate knowledge management into enterprises' strategy, process, organization, performance and other management systems through further system documents, so as to gradually play its role and win more advantages for enterprises in the fierce market competition.

\section{CONCLUSION}

With the advent of the era of knowledge economy, the importance and urgency of knowledge management are becoming more and more prominent. How to optimize the development and utilization of knowledge to create more value for enterprise development is an important issue. The ultimate goal of enterprise knowledge management is to build an effective circulation mechanism of knowledge storage, output and innovation, aiming at the long-term development of enterprises, so that knowledge management can play a maximum role in enterprise management and maximize the benefits of enterprises. Especially for the production, operation and management practice of state-owned enterprises, it is an inevitable choice to gradually bring knowledge management into the scope of enterprise management and gradually establish and improve the structure of enterprise knowledge management system, which complies with the development of the era of knowledge economy.

\section{REFERENCES}

[1] A. Attia, E.I. Essam. Organizational learning, knowledge management capability and supply chain management practices in the Saudi food industry[J]. Journal of Knowledge Management . 2018 (6).

[2] A.A. Alfalih. The role of knowledge management in the transition from entrepreneurial intention to entrepreneurial action in the case of small and medium-sized enterprises[J]. Journal of Information \& Knowledge Management, 2020,19(04).

[3] G. Marianne, S. Danny. Knowledge management and systematic innovation capability[J]. International Journal of Knowledge Management (IJ . 2016 (2).

[4] Z.Y. Li. Fuzzy comprehensive evaluation of enterprise knowledge management execution based on PSCA closed loop [J]. China Management Informatization, 2010 (1): 89-91.

[5] P.F. Liu, Y.T. Wang, C.C. Su. Research on innovation mechanism and path of knowledge management in big data enabling enterprises-based on Huawei case [J]. Scientific and Technological Progress and Countermeasures, 2021,38(01):122131. 